\title{
Pattern and Problems of Xenobiotic Exposure and Envenomation Registry Analysis in North West Region, India
}

\author{
Dr. B Kumar ${ }^{1}$, Dr. Subodh Kumar ${ }^{2}$, Mohamed Ali Jamesha ${ }^{3}$ \\ ${ }^{1}$ Professor, HOD (Medicine) Glocal Medical College Super Speciality Hospital and Research Centre, Saharanpur, UP, India \\ ${ }^{2}$ Assistant Professor, (Biochemistry) Glocal Medical College Super Speciality Hospital and Research Centre, Saharanpur, UP, India \\ ${ }^{3}$ Head HR, Glocal Medical College Super Speciality Hospital and Research Centre, Saharanpur, UP, India
}

\begin{abstract}
Xenobiotic exposure and envenomation are common health hazards in North region in India. World Health Organization (WHO) estimated, 0.3 million people die every year due to various poisoning agents. In the Indian scenario very few studies have been done in North India regarding the epidemiology of poisoning. The present study is focused to analyze the problems, so that meaningful data can be generated for policy formulation regarding treatment of such cases in North West Region, India. Material and Method: The study comprised of 250 poisoning cases collected from various health centers of Glocal Medical College Super Speciality Hospital and Research Centre on 16 point format on all patients treated for any kind of poisoning or envenomation; Then those details were fed into electronic database established at the poisoning and envenomation registry for Saharanpur District and those details were analyzed for various diagnosis parameters (e.g. Ingested/Inhaled/Injected/ Absorption from skin or mucous membranes). Results: During the observation period of two years 250 reports were received from 49 health centers of which 210 were of poisoning/ deliberate selfpoisoning, the rest were of envenomation due to snake bite. Around 50\% were poisoned during traveling and robbed of their belongings. Reports equal that of incident due to deliberate self-harm by pesticides or suicide. Conclusion: Deliberate self-harm or poisoning and envenomation are important health problems in Saharanpur District. In most of the poisoning cases, there were few diagnostic measures used which emphasizes the need of analytical and therapeutical poison Centre in Saharanpur District, which currently has been initiated in Glocal Medical College Super Speciality Hospital. In most of the poisoning and envenomation cases active charcoal, polyvalent ASV could have been incorporated in the treatment of many poisoned patients.
\end{abstract}

Keywords: Charcoal; Polyvalent ASV; Envenomation; XenobioticExposure; Deliberate Self harm;

\section{Introduction}

Xenobiotic exposure and envenomation are common health hazards in North West Region in India. World Health Organization (WHO) estimated, 0.3 million people die every year due to various poisoning agent. ${ }^{1}$ Any drug, toxin, chemical, or naturally occurring substances that results in injury due to exposure to it is, now referred to as a xenobiotic. ${ }^{2}$ In Indian scenario very few studies have been done in Northern India regarding the epidemiology of poisoning. Even though poisoning and envenomation are recognized as very important public health problems, causing enormous morbidity and mortality; there are few organized Government initiated efforts to tackle these problems. The reporting systems on poisoning and envenomation are far from perfect. There are very few poison information centers, and these too are being run more by personal efforts than part of any dedicated Government policies on the above said matter.The most important Objective of our study was to gather comprehensive information about the incidences and the treatment of various cases of poisoning encountered by the physicians in the Glocal Medical College Super Speciality Hospital, Saharanpur in North-west region. The present study was focused to analyze the above discussed problems, so that meaningful data can be generated for Policy Formulation regarding treatment of such cases in North West Region of India.

\section{Material and Method}

The study group of the present study was collected from various health centers (Table-1) of Glocal Medical College Super Specialityand Research Centre. For the creation of the poisoning registry, a detailed study of the subject of clinical toxicology was undertaken from textbooks and reputed journals on the above said matter. ${ }^{3,4,5}$ All aspects of poisoning and envenomation related to occurrence and the circumstances under which that may take place were studied. Many field visits were conducted/organized and interactions with the specialized experts on the subject matter were carried out on the purpose of in-depth study. Based on the input gathered from this research, a 16-point format was designed(Annexure 1: Part B). The study comprised of 250 poisoning cases collected from various health centers of Glocal Medical College Super Speciality Hospital and Research Centre and data was gathered on the 16 point format on all patients treated for any kind of poisoning or envenomation; then those details were fed into electronic database established at the poisoning and envenomation registry for Saharanpur District and those details were analyzed for various diagnosis parameters (e.g. Ingested/ Inhaled/ Injected/ Absorption from skin or mucous membranes). 


\section{International Journal of Science and Research (IJSR) \\ ISSN (Online): 2319-7064}

Index Copernicus Value (2013): 6.14 | Impact Factor (2014): 5.611

\section{Results}

During the observation period of two years; 250 reports were received from 49 health centers of Glocal Medical College Super SpecialityHospial, out of which 210 were of poisoning/ deliberate self-poisoning, the rest were of envenomation due to snake bite (Table $2 \& 4)$. The numbers of reports from Sadolikadeem health centers reported the highest (Table 1). The Patient profiles, who were the victim of poisoning or envenomation, were proportioned to working or dependents status, sex ratio, mean age were summarized(Table 2). The Category: Working/Farmer was affected more than their dependents. The mean age of the victims was 28.85 years. The Course of poisoning was mostly oral 182 (Table- 3).Most victims of envenomation got bitten by snake during duty of work. The circumstances of envenomation are tabulated (Table 4)

A variety of final diagnosis were reported; but maximum number consisted of cases of unknown poisoning (90) followed by pesticides(Fig. 1). The intent of poisoning was mostly suicide or robbery. The findings are graphically represented (Fig.2); Many patients got cured without any intervention. Most needed some supportive therapy. Graphical representation of the kinds of intervention used is represented (Fig.3)

Table 1:

\begin{tabular}{|c|c|c|}
\hline \multicolumn{3}{|c|}{ Reporting Health Centers } \\
\hline S. No & Name of Health Centres & No of cases \\
\hline 1 & Kasimpur & $23^{*}$ \\
\hline 2 & Mirzapur & 2 \\
\hline 3 & Rasanpurpelo & 15 \\
\hline 4 & Taharpur & 9 \\
\hline 5 & Jatowala & $26^{*}$ \\
\hline 6 & Nanuwala & 2 \\
\hline 7 & Mahamoodpur & 4 \\
\hline 8 & Pathanpura & 17 \\
\hline 9 & Shahabdipur & 1 \\
\hline 10 & Jasmor & 18 \\
\hline 11 & Fathehpur & 4 \\
\hline 12 & Chuhudpur & 1 \\
\hline 13 & Nogawa & 9 \\
\hline 14 & Shahpur & 9 \\
\hline 15 & Maganpura & 2 \\
\hline 16 & Manjhipur & 1 \\
\hline 17 & Dayalpur & 4 \\
\hline 18 & Faizabad & 1 \\
\hline 19 & Rahna & 1 \\
\hline 20 & Tanda & 3 \\
\hline 21 & Husainpur & 2 \\
\hline 22 & NoorpurBhrawad & 1 \\
\hline 23 & Kalsiya & 2 \\
\hline 24 & Khurrampur & 1 \\
\hline 25 & Kothri & 4 \\
\hline 26 & Ratanpura & 2 \\
\hline 27 & Haripur & 2 \\
\hline 28 & SadoliKadeem & $30^{* *}$ \\
\hline 29 & Salempur & 1 \\
\hline 30 & Lodipur & 4 \\
\hline 31 & Nanouli & 2 \\
\hline 32 & Sekhpura & 2 \\
\hline 33 & Chko & 1 \\
\hline 34 & Pathed & 2 \\
\hline 35 & Chilkana & 2 \\
\hline
\end{tabular}

Volume 5 Issue 1, January 2016 www.ijsr.net

\begin{tabular}{|l|l|l|}
\hline 36 & Patni & 2 \\
\hline 37 & Usand & 2 \\
\hline 38 & Bubka & 1 \\
\hline 39 & Shafipur & 2 \\
\hline 40 & Doulatpur & 2 \\
\hline 41 & Dauoodpura & 2 \\
\hline 42 & Doodoomajra & 2 \\
\hline 43 & Naglajhanda & 2 \\
\hline 44 & Behat & 15 \\
\hline 45 & Kansepur & 2 \\
\hline 46 & Khushhalpur & 2 \\
\hline 47 & Ashgarpur & 2 \\
\hline 48 & Mayapur & 2 \\
\hline 49 & Chanchak & 2 \\
\hline & TOTAL & 250 \\
\hline
\end{tabular}

Table 2:

\begin{tabular}{|c|c|c|}
\hline \multicolumn{3}{|c|}{ Patient profile of victims of poisoning / envenomation } \\
\hline & Poisoning $(\mathrm{n}=210)$ & Envenomation $(\mathrm{n}=40)$ \\
\hline Patient & Farmer/working $(\mathrm{n}=140)$ & Farmer/working $(\mathrm{n}=28)$ \\
Category & Dependents $(\mathrm{n}=70)$ & Dependents $(\mathrm{n}=12)$ \\
\hline Gender & Males $(\mathrm{n}=170)$ & Males $(\mathrm{n}=30)$ \\
& Females $(\mathrm{n}=40)$ & Females $(\mathrm{n}=10)$ \\
\hline Mean age & Males -28.85 & Males -26.22 \\
& Females -27.08 & Females -31 \\
\hline
\end{tabular}

Table 3:

\begin{tabular}{|c|c|}
\hline \multicolumn{2}{|c|}{ Routes of Poisoning / Envenomation } \\
\hline Route & No. of Poisonings \\
\hline Ingestion & 182 \\
\hline Inhalation & 7 \\
\hline Injection & 1 \\
\hline Absorption from skin & 20 \\
\hline
\end{tabular}

Table 4:

\begin{tabular}{|c|c|}
\hline \multicolumn{2}{|c|}{ Circumstances of Envenomation } \\
\hline Circumstances of Envenomation & No. of Envenomation \\
\hline At work or duty & 22 \\
\hline At play & 4 \\
\hline At home (awake) & 9 \\
\hline At home (asleep) & 5 \\
\hline
\end{tabular}

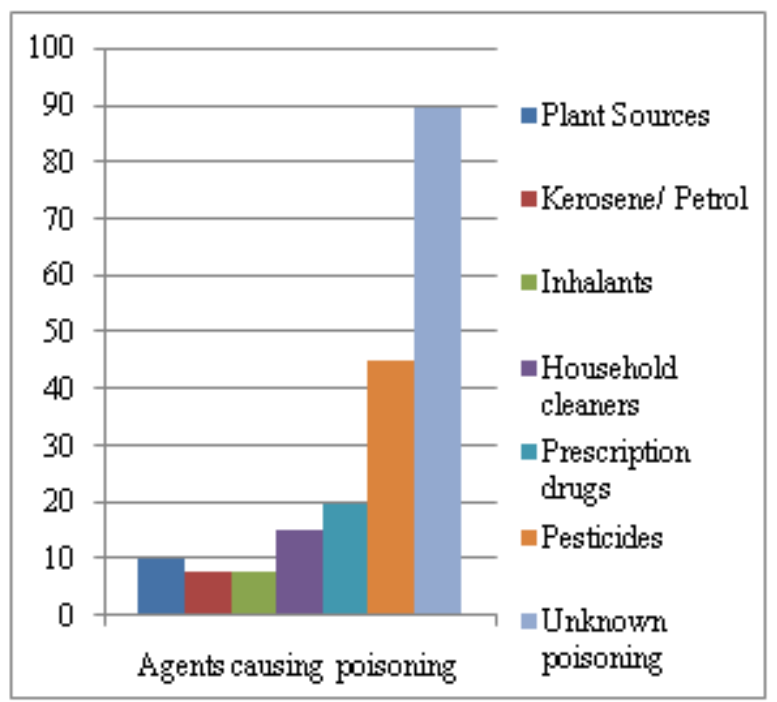

Figure 1: Agents involved in poisoning and the number of patients affected. 


\section{International Journal of Science and Research (IJSR) \\ ISSN (Online): 2319-7064}

Index Copernicus Value (2013): 6.14 | Impact Factor (2014): 5.611

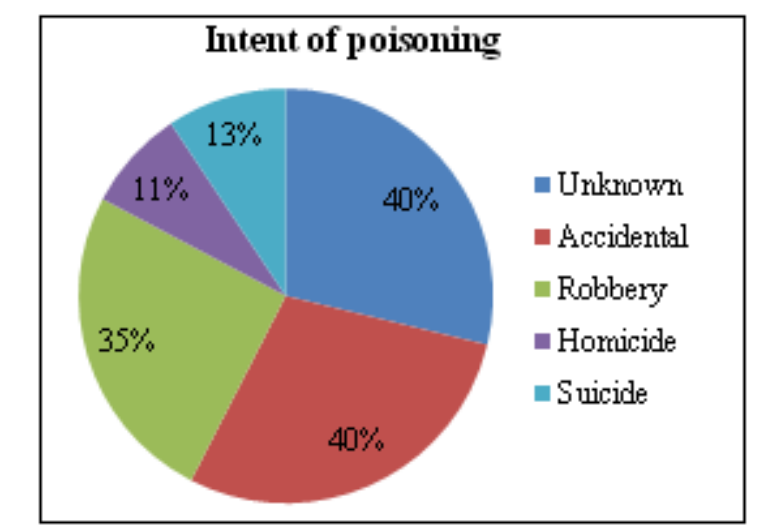

Figure 2: Intent of poisoning

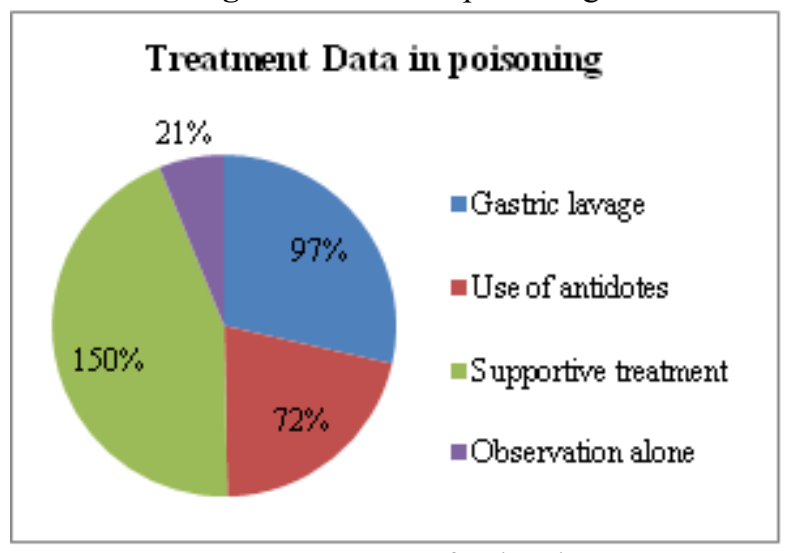

Figure 3: Intent of poisoning

\section{Discussion}

Poisoning is a most common problem in Northern districts of Uttar Pradesh.Saharanpur a tropical region,located at foothills of Shivalik range. The patient profile of the poisoning and envenomation reports reveal that all the reports came from various reporting health centers of Glocal Medical College Super Speciality Hospital and Research Centre, Saharanpur (Table 1). North West Region of India is predominantly agricultural region and therefore, pesticides are found to be the most common cause for acute poisoning with high mortality, due to its high fatality rate. Most common routeof poisoning exposure was Oral, followed by inhalation and dermal exposure(Table 3). Poisoning was seen maximum in younger adults' i.e., 22-29 years. The possible reason for increased poisoning in this age group may be because of poor socio-economic status, unemployment, lack of awareness, which may themselves stressed to attempt suicide(Table 2). In the developing countries poisoning contribute three-fourth of death due to self-harm; India being a developing country, our findingsare in tune with the trends in this context. ${ }^{6}$ Pesticides are the principal cause of poisoning in most of the developing countries. ${ }^{7,8}$ Our data supports such findings. Ingestion is a common form of deliberate self- harm due to the relative ease of availability compared to others. ${ }^{9}$ Our statistics on the contribution of pesticidesare mainly organophosphates and their capacity to cause dangerous toxicity matches well with existing literature.Globally, the prescription of drug-related overdose; accidental as well as due to attempted deliberate self-harm, form a very large proportion of causes of poisoning. ${ }^{10}$ Activated charcoal has a very important place in the management of poisoning. ${ }^{11,12}$ Previous workshas shown the effect of Polyvalent anti-snake venom in various snake bite cases without any adverse reaction. ${ }^{13,14}$ On the basis of present study and previous work it has been observed that there is an alarming increase in cases of poisoning. Deliberate self-harm or poisoning and envenomation are important health problems in Saharanpur District/North West Region.

\section{Conclusion}

In most of the poisoning cases, there were few diagnostic measures used which emphasizes the need of analytical and therapeutical poison Centre in Glocal Medical College Super Speciality Hospital. In most of the poisoning and envenomation cases active charcoal, polyvalent ASV should be incorporated in treatment of poisoned patients.Above all, increase in public awareness about the seriousness of problem due to Xenobiotics exposure should be carried out on a wide scale which would result in decrease of cases reported on the same.

\section{Intellectual Contributions of Authors}

Study Concept: Prof Dr B Kumar,Dr. Subodh Kumar Drafting and manuscript revision: Prof Dr B Kumar, DrShamsudeen, Mohamed Ali Jamesha

Statistical analysis: Prof Dr B Kumar, Mohamed Ali Jamesha

Study supervision: Prof Dr B Kumar, DrShamsudeen

\section{Conflict of Interest}

The present study has been sponsored by Chairman, Haji. Mohamed Iqbal(*M.L.C.), Glocal Medical College Super Speciality Hospital, Saharanpur, U.P., India

\section{References}

[1] Thundiyil JG, Stober J, Besbelli N, Pronczuk J. Acute pesticide poisoning: a proposed classification tool.Bull World Health Organ. 2008;86:205-9

[2] Correia MA. Drug Biotransformation. In Basic and clinical pharmacology, $10^{\text {th }}$ ed. KatzungBG,ed. USA: McGraw Hill Inc, 2007:50-63

[3] Parikh CK. Text- Book of Medical Jurisprudence, Forensic Medicine and Toxicology, $6^{\text {th }}$ ed. CBS Publishers and Distributors, New Delhi, Indian edition 1999,p. 10:44

[4] Burda AM, Burda NM. The nation's first poison control center: taking a stand against accidental childhood poisoning in Chicago. Vet Human Toxicol 1999;39:115119.

[5] Daly FFS, Murray LM, Little M, Dart RC. Specialisedcentres for the treatment of poisoned patients. In: Medical Toxicology, $3^{\text {rd }}$ ed, Dart RC, ed. Philadelphia: Lipincott Williams and Wilkins, 2004:6-9.

[6] Wesseling C, McConnel R, Partanen T, Hogstedt C. Agricultural pesticide use in developing countries: health effects and research needs. Int J Health Serv 1997;24:273-308. 


\section{International Journal of Science and Research (IJSR) \\ ISSN (Online): 2319-7064}

Index Copernicus Value (2013): 6.14 | Impact Factor (2014): 5.611

[7] Eddleston M. Pattern and Problems of deliberate selfpoisoning in the developing world. Q J Med 2000;93:715-731.

[8] Jeyaratnam J. Acute pesticide poisoning: major global health problem. World Health Stat Q 1990;43:139-144.

[9] Eddleston M, Karunaratne A, Weerakoon $M$ et al. Choice of poison for intentional self-poisoning in rural Sri Lanka. ClinToxicol (Phila) 2006;44:283-286.

[10] Wolfle J, Kowalewski S. Epidemiology of ingestions in a regional poison control center over twenty years. Vet Hum Toxicol 1995;37:367-368.

[11] Todd JW. Do measures to enhance drug removal save life? Lancet 1984;i:331.

[12] Vale JA, Proudfoot AT. How useful is activated charcoal? Br Med J 1993;306:78-79.

[13] Theakston, R.D.G., Warrell, D.A., Griffiths, E. Report of a WHO workshop on the standardization and control of antivenoms. Toxicon. 2003;41:541-557.

[14] Chippaux, J.P. Snakebites: appraisal of the global situation. Bull World Health Org. 1998;76:515-524

\section{Annexure 1:}

\section{Poisoning Registry:}

\section{Part 'A'}

Comprises of Instructions for filling the profromaPart ' $\mathrm{B}$ ' to report a case of poisoning, envenomation.

\section{Part 'B'}

Comprises Statistics of Details related to Patient and treatment carried out by the Physician, its outcome and final remarks by Physician. 